\title{
Alih Kode dan Campur Kode oleh Pegawai Aerotravel di Denpasar
}

\author{
Ni Putu Novi Prasanthi ${ }^{1 *}$, Ni Made Andry Anita Dewi ${ }^{2}$, Ni Luh Kade Yuliani Giri ${ }^{3}$ \\ ${ }^{[123]}$ Program Studi Sastra Jepang Fakultas Ilmu Budaya \\ 1email:veeprasanthi@gmail.com] ${ }^{2}$ [email:andry_anita@unud.ac.id] \\ ${ }^{3}$ [email:giri222000@yahoo.com] \\ *Corresponding Author
}

\begin{abstract}
Abstrak
Penelitian ini berjudul "Alih Kode dan Campur Kode oleh Pegawai Aerotravel di Denpasar". Tujuan penelitian ini adalah untuk mengetahui jenis dan faktor penyebab alih kode dan campur kode yang terjadi dalam komunikasi di biro perjalanan wisata Aerotravel. Data pada penelitian ini dianalisis dengan metode agih dan padan. Data terdiri dari dua buah bahasa yang berbeda, yaitu bahasa Jepang dan bahasa Indonesia. Pada masing-masing bahasa tersebut saling dihubungkan sehingga ditemukan jenis dan faktor penyebab alih kode dan campur kode. Teori yang digunakan pada penelitian ini adalah teori jenis dan faktor penyebab alih kode menurut Wardhaugh (2006), jenis campur kode menurut Hoffman (1991), dan faktor penyebab campur kode menurut Weinrich (1979). Hasil dari penelitian ini adalah dari 20 data yang terdapat dalam komunikasi di Aerotravel, ditemukan 6 jenis alih kode dan 14 jenis campur kode. Alih kode yang ditemukan termasuk jenis methaporical code switching sebanyak 1 buah data dan situational code switching sebanyak 5 buah data. Campur kode yang ditemukan termasuk jenis campur kode dalam leksikal sebanyak 10 buah data, campur kode dalam fonologis sebanyak 3 buah data, dan campur kode dalam kalimat sebanyak 1 buah data. Faktor penyebab terjadinya alih kode adalah topik, solidaritas dengan kawan tutur, jarak sosial dan budaya, dan motivasi. Faktor penyebab terjadinya campur kode adalah low frequency of word (frekuensi penggunaan kata yang rendah), need for synonym (keterbatasan kata), social value (nilai sosial), familiarity with another culture (perkenalan dengan budaya baru), dan in sufficiency differentiated (makna bahasa yang kurang detail). Dapat ditarik kesimpulan bahwa alih kode yang banyak digunakan adalah situational code switching. Latar belakang pendidikan menjadi salah satu penyebab terjadinya campur kode.
\end{abstract}

Kata kuci : alih kode, campur kode, komunikasi.

\begin{abstract}
This research aims to identify types and causes of code switching and code mixing that are applied at Aerotravel Denpasar. This research is analyzed with "Agih and Padan" method in two different languages, Japan and Indonesian. On each of the language, it's connected therefore found type and cause of factor code switching and code mixing. The theories used are code switching (Wardhaugh, 2006), code mixing (Hoffman, 1991), and cause code mixing factor (Weinrich, 1979). From 20 data that is analyzed at Aerotravel, it resulted 6 type switching code: 1 methaporical code switching, 5 situational code switching. In addition there are 14 data of switching code consists of 10 lexical code mixing in lexical, 3 phonologic code mixing, and 1 sentence code mixing. The cause factors of switching codes are, topic, solidarity with communicator, social art distance, and motivation. The cause factor of code mixing are low frequency of word, need for synonym, social value, familiarity with another culture, and sufficiency differentiated. This research concludes that
\end{abstract}


the situational code switching is the most used in code switching. Education background is the cause of code mixing existence.

Keyword: code switching, code mixing, communication

\section{(1) Latar Belakang}

Lingkungan di sekitar penutur memiliki pengaruh besar pada pilihan bahasa yang digunakan oleh penutur dalam berkomunikasi. Salah satu contoh dari hal tersebut adalah adanya fenomena alih kode dan campur kode. Alih kode yaitu peralihan atau perpindahan atau pergantian dari suatu varian bahasa ke bahasa yang lain (Wardhaugh, 2006:101). Sedangkan campur kode adalah pencampuran dua atau lebih bahasa di dalam satu kalimat (Hoffmann, 1991:104). Alih kode dan campur kode yang dilakukan penutur dan lawan tuturnya merupakan jembatan komunikasi yang efektif sehingga komunikasi menjadi lebih lancar. Namun, hal yang menarik adalah masalah alih kode dan campur kode yang terjadi akibat adanya masyarakat yang memiliki kemampuan bilingualisme maupun multilingualisme. Alih kode dan campur kode menjadi masalah yang menarik untuk dikaji karena memiliki keterkaitan yang sangat erat dengan bilingualisme dan multingualisme.

Penelitian ini yang menjadi fokus penelitian adalah alih kode dan campur kode oleh pegawai di biro perjalanan wisata Aerotravel divisi Jepang atau nama lain dari divisi ini adalah Garuda Orient Holiday (GOH Japan). Aerotravel berlokasi di Jalan By Pass Ngurah Rai No. 11 A, Kuta Kabupaten Badung Bali. Lingkungan biro perjalanan wisata ini menuntut pegawai berkebangsaan Jepang agar dapat memiliki kemampuan bilingualisme maupun multilingualisme untuk berinteraksi dengan lawan tuturnya.
Kemampuan bilingualisme dan multilingualisme yang cukup tinggi mengakibatkan frekuensi terjadinya alih kode dan campur kode antara pegawai berkebangsaan Jepang dengan karyawan lokal berkebangsaan Indonesia cukup tinggi. Oleh sebab itu, penulis tertarik untuk menganalisis masalah alih kode dan campur kode yang terjadi di biro perjalanan wisata Aerotravel.

\section{(2) Pokok Permasalahan}

Berdasarkan uraian latar belakang tersebut, maka rumusan permasalahan penelitian ini adalah sebagai berikut:

a. Bagaimanakah jenis dan faktor penyebab alih kode pegawai Aerotravel di Denpasar?

b. Bagaimanakah jenis dan faktor penyebab campur kode pegawai Aerotravel di Denpasar?

\section{(3) Tujuan Penelitian}

Secara umum, penelitian ini bertujuan untuk memperkaya khasanah penelitian sosiolinguistik khususnya peristiwa kebahasaan alih kode dan campur kode dengan komunikasi lisan sebagai objek penelitiannya. Secara khusus, penelitian bertujuan untuk mengetahui jenis dan faktor penyebab alih kode dan campur kode pegawai Aerotravel di Denpasar.

\section{(4) Metode Penelitian}

Terdapat beberapa metode yang digunakan dalam penelitian ini. Pertama, metode dan teknik pengumpulan data yang digunakan adalah metode simak dan teknik 
sadap. Kedua, metode dan teknik analisis data yang digunakan adalah metode agih dan padan. Ketiga, metode dan teknik penyajian hasil analisis data yang digunakan adalah metode informal. Selain itu, teori yang digunakan untuk memecahkan permasalahan adalah teori mengenai alih kode yang dikemukakan oleh Wardhaugh (2006) dan teori mengenai campur kode yang dikemukakan oleh Hoffmann (1991) dan Weinrich (1979).

\section{(5) Hasil dan Pembahasan}

Terdapat 20 data alih kode dan campur kode yang terjadi di Aerotravel.

\subsection{Jenis dan Faktor Penyebab Alih Kode}

Terdapat dua buah jenis alih kode yang terjadi dalam komunikasi di Aerotravel dan juga faktor penyebab alih kode.

\subsubsection{Metaphorical Code Switching Metaphorical code switching} adalah alih kode yang terjadi saat adanya pergantian topik pembicaraan. Hasil analisis menunjukkan bahwa terdapat satu data yang merupakan jenis methaporical code switching dan faktor penyebabnya adalah topik pembicaraan disertai dengan lawan tutur yang berbeda.

(1) Ono: Jadi totalnya berapa yang dapat dari sini?

Eka : 320 ribu

Ono: Mereka minum di mana?

Eka : Mereka ya minum di situ

Ono: (Mengangkat telepon)

はい、GOH Japan でご

ざいます。はい、明日何

時に出発しますか。はい、

わかりました,お疲れ様で

\section{す。}

Ono : Jadi totalnya berapa yang dapat dari sini?

Eka : 320 ribu

Ono : Mereka minum di mana?

Eka : Mereka ya minum di situ

Ono : (Mengangkat telepon)

Hai, GOH Japan de gozaimasu. Hai, ashita nanji ni shuppatsu shimasuka? Hai, wakarimashita. Otsukaresamadesu.

Terjemahan:

Ono : Jadi totalnya berapa yang dapat dari sini?

Eka : 320 ribu

Ono : Mereka minum di mana?

Eka : Mereka ya minum di situ

Ono : (mengangkat telepon)

Ya disini GOH Japan. Iya, besok jam berapa pesawatnya datang? Iya, saya mengerti, terima kasih atas kerjasamanya.

Berdasarkan percakapan tersebut ditemukan alih kode pada kalimat "mereka minum dimana?. Hai, GOH Japan de gozaimasu. Hai ashita nanjini shuupatsu shimasuka. Hai, wakarimashita, otsukaresamadesu”. Kalimat tersebut termasuk dalam jenis methaporical code switching. Hal ini disebabkan adanya alih kode dari bahasa Indonesia ke bahasa Jepang dengan topik yang berbeda. Pada kalimat "mereka minum dimana?" yang diucapkan oleh Ono untuk membahas wellcome drink yang akan diberikan kepada kelompok tamu yang menggunakan jasa Aerotravel. Kemudian pada kalimat 
selanjutnya Ono melakukan alih kode ke bahasa Jepang yaitu, "Hai, GOH Japan de gozaimasu. Hai ashita nanjini shuupatsu shimasuka. Hai, wakarimashita, otsukaresamadesu", ketika menerima telepon SLI (Saluran Langsung Internasional) dari pegawai maskapai penerbangan Garuda cabang Osaka. Pada percakapan alih kode yang digunakan oleh Ono disebabkan oleh faktor perubahan topik dan perubahan lawan tutur. Topik pembicaraan berubah dari sesuatu yang berkaitan dengan wellcome drink menjadi pembicaraan mengenai kedatangan tamu dari Jepang. Selain itu, perubahan lawan tutur dari pegawai Aerotravel ke pegawai maskapai penerbangan Garuda cabang Osaka menjadi faktor penyebab terjadinya alih kode.

\subsubsection{Situational Code Switching}

Situatinal code switching adalah alih kode yang terjadi jika ada perubahan situasi. Hasil analisis menunjukkan data seperti berikut.

(2) Ono: 待ってるほど

Eka : Oh tidak bisa.

Ono: Bekerja bersatu?

Eka : Lagi dengan mbok dek?

Dulu sudah pisah sama saya.

Ono : Matteru hodo

Eka : Oh tidak bisa.

Ono : Bekerja bersatu?

Eka : Lagi dengan mbok dek?

Dulu sudah pisah sama saya.

Terjemahan :

Ono : Saya masih menunggu

Eka : Oh tidak bisa.

Ono : Bekerja sama?

Eka : Dengan mbok dek lagi?

Dulu sudah pisah sama saya.
Data (2) menunjukkan adanya alih kode pada tuturan "matteru hodo", "oh tidak bisa". Tuturan tersebut termasuk dalam jenis situational code switching. Hal ini ditunjukkan dengan adanya alih kode bahasa Jepang ke bahasa Indonesia yang disebabkan situasi, yaitu Eka yang tidak begitu menguasai bahasa Jepang menanggapi tuturan Ono. Pada tuturan yang diucapkan oleh Ono yaitu, "matteru hodo" yang memiliki maksud menunggu keputusan Eka untuk melakukan tugas kantor dengan pegawai Aerotravel bernama Kadek. Selanjutnya Eka mengalihkan bahasa yang awalnya tuturan menggunakan bahasa Jepang menjadi bahasa Indonesia untuk menanggapi tuturan Ono yaitu dengan berkata, "oh tidak bisa". Percakapan alih kode ini terjadi karena faktor solidaritas dengan kawan tutur. Ono mengetahui Eka tidak begitu menguasai bahasa Jepang, sehingga Ono mengalihkan tuturannya dari bahasa Jepang ke bahasa Indonesia.

\subsection{Jenis dan Faktor Penyebab Campur Kode}

Terdapat tiga buah jenis campur kode yang terjadi dalam komunikasi di Aerotravel dan juga faktor penyebab campur kode.

\subsubsection{Campur Kode dalam Leksikal}

Campur kode dalam leksikal adalah pencampuran dua bahasa berbeda dalam batas kata. Hasil analisis menunjukkan data sebagai berikut.

$$
\begin{gathered}
\text { Ono : 今アグンさん Idulfitri } \\
\text { ですよ } \\
\text { Agung : (Mengangguk) } \\
\text { Ono : Ima Agung san Idulfitri } \\
\text { desuyo. } \\
\text { Agung : (Mengangguk) }
\end{gathered}
$$


Terjemahan:

Ono : Sekarang Agung merayakan Idulfitri kan.

Agung : (Mengangguk)

Berdasarkan tuturan tersebut ditemukan campur kode pada kata "Idulfitri". Campur kode tersebut termasuk campur kode dalam leksikal. Ono menggunakan kata "Idulfitri" dalam tuturannya karena tidak adanya istilah khusus untuk menerangkan kata "Idulfitri" dalam bahasa Jepang. Oleh karena itu, ia menggunakan kata dalam bahasa Indonesia yang lebih dianggap mampu untuk menyampaikan maksud tuturannya. Kebutuhan untuk mendapatkan sinonim menjadi faktor Ono untuk melakukan campur kode.

\subsubsection{Campur Kode dalam Fonologis}

Campur kode dalam fonologis adalah kata dalam bahasa Inggris namun dimodifikasi ke dalam struktur fonologi bahasa Jepang. Hasil menunjukkan data sebagai berikut.

$$
\begin{aligned}
& \text { Mai : おじいちゃんたちはグル } \\
& \text { 一プでしょう。 } \\
& \text { Ono : ダッブルダッブルだった } \\
& \text { らしだよ。 } \\
& \text { Mai : Ojii chan tachi wa guruupu } \\
& \text { deshou } \\
& \text { Ono : Dabburu dabburu datta } \\
& \text { rashii dayo. } \\
& \text { Terjemahan: } \\
& \text { Mai : Kakek-kakek ini grup kan? } \\
& \text { Ono : Sepertinya berpasang- } \\
& \text { pasangan. }
\end{aligned}
$$

Berdasarkan tuturan tersebut ditemukan campur kode pada kata "guruupu" dan "dabburu". Campur kode tersebut termasuk campur kode dalam fonologis. "Guruирu" dan "dabburu" berasal dari bahasa Inggris yaitu "group" dan "double". "Group" dan "double" dimodifikasikan ke dalam struktur fonologi bahasa Jepang menjadi gитиири dan dabburu. Faktor penyebab penggunaan campur kode yaitu keterbatasan kata. Kata "dabburu" tidak memiliki padanan dalam bahasa Jepang, sedangkan kata "guruppu" memiliki padanan yaitu kata "syuudan". Namun kata "syuudan" tidak dapat berdiri sendiri, harus diikuti kata benda di depannya seperti "dai syuudan" yang artinya kelompok besar. Oleh karena itu kata "guruppu" digunakan karena dapat berdiri sendiri tanpa harus megikuti kata benda. Keterbatasan kata menjadi faktor penyebab Mai dan Ono melakukan campur kode.

\subsubsection{Campur Kode dalam Kalimat}

Campur kode dalam kalimat adalah pencampuran dua bahasa yang berbeda dalam tataran kalimat. Hasil analisis menunjukkan data sebagai berikut.

Matsumoto: こちください

Ono：でもあってます

Matsumoto: Just taking photo うれしい

Mai : そうなんですよ

Matsumoto : Kochi kudasai

Ono : Demo attemasu

Matsumoto : Just taking photo ureshii

Mai : Sounandesuyo

Terjemahan: 


$$
\begin{array}{ll}
\text { Matsumoto } & \text { Tolong ke sini } \\
\text { Ono } & \text { : Tapi sudah benar } \\
\text { Matsumoto } & \text { Hanya mengambil } \\
& \text { foto, senangnya } \\
\text { Mai } & \text { : Iya }
\end{array}
$$

Berdasarkan tuturan pada data (5) ditemukan campur kode pada kalimat "just taking photo ureshii”. Just taking photo adalah sebuah kalimat utuh yang berarti hanya mengambil foto. Faktor penyebab penggunaan campur kode yang dilakukan Matsumoto yaitu nilai sosial. Matsumoto ingin menunjukkan gengsinya bahwa ia mampu menggunakan bahasa asing, yaitu bahasa Inggris. Bahasa Inggris merupakan bahasa internasional sehingga penggunaannya dianggap bergengsi dan menimbulkan efek yang positif.

\section{(6) Simpulan}

Berdasarkan data yang telah dianalisis, ditemukan jenis alih kode yang terdapat di Aerotravel, yaitu methaporical code switching dan situational code switching. Jumlah jenis alih kode yang ditemukan adalah satu data methaporical code switching dan lima data situational code switching. Faktor penyebab alih kode yang ditemukan antara lain topik, solidaritas dengan kawan tutur, jarak sosial dan budaya, dan motivasi.

Campur kode yang ditemukan, yaitu campur kode dalam leksikal, fonologis, dan kalimat. Jumlah jenis campur kode yang ditemukan adalah 10 data campur kode dalam leksikal, tiga data campur kode dalam fonologis, dan satu data campur kode dalam kalimat. Latar belakang pendidikan menjadi faktor penyebab terjadinya campur kode. Selain itu, faktor penyebab lainnya yang ditemukan di Aerotravel hanya ada lima buah dari tujuh faktor penyebab campur kode berdasarkan teori yang dikemukakan oleh Weinrich (1979), yaitu low frequency of word (frekuensi penggunaan kata yang rendah), need for synonym (keterbatasan kata), social value (nilai sosial), familiarity with another culture (perkenalan dengan budaya baru), dan in sufficiency differentiated (makna bahasa yang kurang detail).

\section{(7) Daftar pustaka}

Hoffmann, Charlotte. 1991. An Introduction to Bilingualism. New York: Longman.

Wardhaugh, Ronald. 2006. An Introduction to Sociolinguistic. Great Britain:

Blackwell.

Weinreich, Uriel. 1979. Language in Contact : Finding and Problem. New York: Mouton Publishers the Houge. 